\title{
Construction of a Novel Gene Bank of Bacillus subtilis Using a Low Copy Number Vector in Escherichia coli
}

\author{
By SHAHIDA HASNAIN† AND CHRISTOPHER M. THOMAS* \\ Department of Genetics, University of Birmingham, PO Box 363, Birmingham B15 2TT, UK
}

(Received 18 December 1985; revised 23 February 1986)

\begin{abstract}
Low copy number vector plasmid pCT571 was constructed to clone Bacillus subtilis genomic fragments in Escherichia coli. pCT571 confers $\mathrm{Km}^{\mathrm{R}}, \mathrm{Tc}^{\mathrm{R}}$ and $\mathrm{Cm}^{\mathrm{R}}$ in $E$. coli and $\mathrm{Cm}^{\mathrm{R}}$ in $B$. subtilis. It has unique restriction sites within the $\mathrm{Km}^{\mathrm{R}}$ and $\mathrm{Tc}^{\mathrm{R}}$ markers to allow screening for recombinant plasmids by insertional inactivation of these genes. It contains the pSC101 replicon and replicates normally at six to eight copies per chromosome equivalent in $E$. coli. It also contains ori $V_{\mathrm{RK} 2}$, which when supplied with the product of the $\operatorname{trf} A$ gene of RK2 in trans, allows pCT571 to replicate at 35-40 copies per chromosome equivalent. A B. subtilis gene bank was created by cloning partially Sau3A-digested and size-fractionated fragments of $B$. subtilis chromosomal DNA into the BamHI site of pCT571. DNA from $1097 \mathrm{Km}^{\mathrm{R}} \mathrm{Tc}^{\mathrm{S}}$ transformants was extracted and analysed electrophoretically as supercoiled DNA and after digesting with EcoRI or EcoRI and SalI. Approximately 1000 hybrid plasmids were found with reasonably sized $B$. subtilis fragments. The mean size of the inserts in pCT571 is $8 \mathrm{~kb}$, ranging from 4 to $20 \mathrm{~kb}$ in different plasmids. The gene bank covers most of the $B$. subtilis chromosome, as demonstrated by the results of screening the gene bank for selectable nutritional markers in $E$. coli and $B$. subtilis. Hybrid plasmids which complement $E$. coli mutants for arg, his, lys, met, pdx, pyr and $t h r$ markers were identified from the gene bank. In $B$. subtilis the presence of $\arg C, c y s A$, $\operatorname{dal}$, his $A$, ilvA, leuA, lys, metB, metC, phe, purA, purB, thr and $\operatorname{trp} C$ was established by transformation experiments. The effects of copy number on cloning and long-term maintenance in the bacterial strains were also investigated. At high copy number some hybrid plasmids cannot be maintained at all, while others show an increased rate of structural deletions and rearrangements.
\end{abstract}

\section{INTRODUCTION}

The use of high copy number plasmid cloning vectors has the advantages of allowing the isolation of large amounts of cloned DNA fragments and also aids the purification of proteins coded by the cloned genes. While partially successful attempts have been made to prepare, in Escherichia coli, plasmid gene banks of the Bacillus subtilis genome, using fragments produced by shearing or by digestion with restriction endonucleases (Hutchinson \& Halvorson, 1980; Rapoport et al., 1979; Ostroff \& Pène, 1984a,b), a number of problems have been encountered. The final gene bank often has a less than random assortment of relatively small genomic fragments (Hutchinson \& Halvorson, 1980; Gryczan \& Dubnau, 1982). This may be due to the dosage of cloned genes joined to high copy number plasmids having deleterious effects on the bacterial host (Banner et al., 1983), as well as promoting instability of the inserted segment. Ostroff \& Pène $(1984 a, b)$ succeeded in cloning 8-9 kb fragments of $B$. subtilis DNA in a bifunctional plasmid vector in $E$. coli as an intermediate host, but a variety of their cloned fragments were unstable, and they observed deletions of both the insert and vector plasmid sequences when hybrid plasmids were returned to $B$. subtilis.

† Present address: Department of Botany, New Campus, Punjab University, Lahore-20, Pakistan. 
In specific cases (for example, Mountain et al., 1984) it has been observed that some of these problems can be avoided by using low copy number cloning vectors. We therefore set out to construct a gene bank representative of the $B$. subtilis chromosome in a reasonably small, low copy number plasmid vector. However, we thought it desirable to design the vector so that the copy number could be increased under specific conditions. This should not only facilitate the isolation of hybrid plasmid DNA and purification of the products of cloned genes but should also allow us to determine whether deleterious effects on the host or structural instability of the hybrid plasmid at high copy number are a common problem with clones selected randomly from such a gene bank.

Here we report the construction of the vector pCT571, its use in the production and screening of a gene bank of $B$. subtilis in $E$. coli and the effects of high copy number on hybrid plasmids from this gene bank.

\section{METHODS}

Bacterial strains and plasmids. Bacterial strains used in this study are shown in Table 1. Previously described plasmids used for the construction of the vector pCT571 were pLG339 (Stoker et al., 1982), pCT461 (Thomas, 1983) and pHV60 (from Myra Jacobs, G. D. Searle Ltd, High Wycombe, UK) which is indistinguishable from pHV32 (Primrose \& Ehrlich, 1981). Plasmid pUC99 (from R. Sammons, University of Birmingham, UK) was constructed by inserting an $8.2 \mathrm{~kb}$ EcoRI fragment carrying the his genes of $B$. subtilis into pUC9 (Vieira \& Messing, 1982). Plasmids constructed during the course of this work are described in the text.

Bacterial growth. Growth medium for E. coli was L-broth (Kahn et al., 1979), which was solidified with $1.5 \%$ (w/v) agar for $\mathrm{L}$-agar. Incubation was at $37^{\circ} \mathrm{C}$. For the selection of antibiotic resistance markers $\left(\mathrm{Km}^{\mathrm{R}}, \mathrm{Tc}^{\mathrm{R}}, \mathrm{Cm}^{\mathrm{R}}\right.$ and $\left.\mathrm{Pn}^{\mathrm{R}}\right)$ carried by plasmids, medium was supplemented with kanamycin $\left(50 \mu \mathrm{g} \mathrm{ml}^{-1}\right)$, tetracycline $\left(25 \mu \mathrm{g} \mathrm{ml}^{-1}\right)$, chloramphenicol $\left(5 \mu \mathrm{g} \mathrm{ml}^{-1}\right)$ and penicillin $\left(300 \mu \mathrm{g} \mathrm{ml}^{-1}\right)$. For the selection of nutritional markers, M9 minimal agar (Kahn et al., 1979) was supplemented with growth requirements (for amino acids, at $50 \mu \mathrm{g} \mathrm{ml}^{-1}$ ), except those for which selection was made.

For B. subtilis, potato/glucose/yeast extract (PGYE) agar and Difco Penassay broth were used as rich media. Minimal medium (Anagnostopoulos \& Spizizen, 1961) was supplemented with glucose $(0.5 \%)$ and amino acids $\left(50 \mu \mathrm{g} \mathrm{ml}^{-1}\right)$ where required. Growth was at $37^{\circ} \mathrm{C}$ or $42^{\circ} \mathrm{C}$.

Transformation of bacteria. E. coli strains were made competent essentially as described by Thomas (1981). B. subtilis strains were transformed as described by Anagnostopoulos \& Spizizen (1961).

Preparation of DNA. Plasmid DNA was extracted by the alkaline-SDS method of Birnboim \& Doly (1979) as modified by Smith \& Thomas (1983). B. subtilis chromosomal DNA was prepared according to Marmur (1961).

Manipulation of DNA. Restriction endonucleases were obtained from BRL, P \& S Biochemicals Ltd or NBL Enzymes and used under conditions similar to those recommended by the suppliers. Terminal 5' phosphates were removed from plasmid vector DNA using calf intestinal alkaline phosphatase (BCL). Partially Sau3A-digested chromosomal DNA of $B$. subtilis was fractionated by velocity centrifugation through a sucrose density gradient to isolate fragments in the range of $4-20 \mathrm{~kb}$ as described by Maniatis et al. (1978). Agarose gel electrophoresis was done under standard conditions.

\section{RESULTS}

\section{Construction of the vector plasmid pCT571}

The first step in the construction of this vector was the derivation of a new plasmid with reasonably small size and a copy number which, while normally low, can be increased under particular circumstances. This was achieved using plasmids pLG339 and pCT461. Plasmid pLG339, which is derived from pSC101, has a copy number of six to eight per chromosome in $E$. coli and confers resistance to tetracycline and kanamycin (Stoker et al., 1982). Plasmid pCT461 is a mini RK2 ( $E$. coli $\mathrm{IncP})$ derivative. The two regions essential for replication of this plasmid are $\operatorname{ori} V_{\mathrm{RK} 2}$, the vegetative replication origin, and the $\operatorname{trf} A$ gene, whose protein product acts positively in trans to allow initiation of plasmid replication (Thomas, 1981). It has a copy number of 35-40 per chromosome due to deletions in the ori $V_{\mathrm{RK} 2}$ region (Thomas et al., 1984), and was used as the source of a fragment carrying a mutant ori $V_{\mathrm{RK} 2}$ which when supplied with 
Table 1. Bacterial strains

\begin{tabular}{|c|c|c|}
\hline Strain & Description & Reference or source* \\
\hline \multicolumn{3}{|l|}{ E. coli $\mathrm{K} 12$} \\
\hline MV10 & C600 $\Delta$ trpE5 (thr-1 leu-6 thi-1 lacYI supE44 tonA2I trpE5) & D. R. Helinski \\
\hline $\mathrm{MV} 10 \mathrm{Ch} 3 / 86$ & $\begin{array}{l}\text { MV10 carrying hybrid } \lambda \text { prophage } \mathrm{Ch} 3 / 86 \text { with } \operatorname{trf} A \text { and } \operatorname{tr} f B \text { regions of } \\
\text { plasmid RK } 2\end{array}$ & Thomas et al. (1981) \\
\hline HB101 & $\begin{array}{l}\mathrm{F}^{-} h s d S 20\left[\operatorname{Res}^{-} \mathrm{Mod}^{-}(\mathrm{B})\right] \text { recAl3 ara-14 lacY1 proA2 galK2 rpsL20 } \\
\left(\mathrm{Sm}^{\mathrm{R}}\right) \text { xyl-5 mtl-1 supE } 44 \lambda^{-}\end{array}$ & D. R. Helinski \\
\hline ED8654 & supE supF $h s d R^{-} M^{+} S^{+}$met trpR & $\begin{array}{l}\text { J. Guest; } \\
\text { Murray et al. (1977) }\end{array}$ \\
\hline 2235 & his argH thr leu trp cys $A$ phe mil lac gal $r p s L\left(\mathrm{Sm}^{\mathrm{R}}\right)$ malA $\left(\mathrm{Muc}^{+}\right)$ & Departmental stock \\
\hline 2848 & {$\left[\mathrm{R}_{100-1}\left(\mathrm{Tc}^{\mathrm{S}}\right)\right] \lambda^{+}$his trp lys gal malB rpsL $\left(\mathrm{Sm}^{\mathrm{R}}\right)$} & Departmental stock \\
\hline 2608 & $\begin{array}{l}\text { pyrF } 30 \text { ilv-277 met-65 his-53 purE4I proC } 24 \text { pdxC } 3 \text { xyl-14 lac Y } 29 \text { str-97 } \\
\text { cyc-2 cycAI tonA32 }\end{array}$ & Departmental stock \\
\hline \multicolumn{3}{|c|}{ 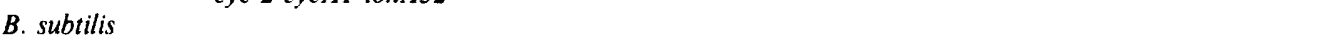 } \\
\hline PY79 & Prototroph & Youngman et al. (1984) \\
\hline 1606 & leuA met $A$ thy $A$ thyB & N. Sueoka \\
\hline 1612 & dal-I aroI sacA metB & Departmental stock \\
\hline $1 \mathrm{~A} 10$ & $\operatorname{trpC} 2$ his Al thr-5 & R. Dedonder \\
\hline $1 \mathrm{A3}$ & $\operatorname{trp} C 2$ cys A14 purAl6 & R. Dedonder \\
\hline lA5 & $\operatorname{trp} C 2$ glyB 733 metC3 & R. Dedonder \\
\hline 1412 & purA16 lys-21 phe-12 metB5 arg-3 & Departmental stock \\
\hline 1458 & ilvA $\operatorname{trp} C 2$ & C. Anagnostopoulos \\
\hline 1411 & purB6 leu-8 metB5 & N. Sueoka \\
\hline 1417 & hisAl $\operatorname{argC4}$ & Departmental stock \\
\hline
\end{tabular}

* D. R. Helinski, University of California, San Diego, USA; J. R. Guest, Department of Microbiology, University of Sheffield, UK; N. Sueoka, University of Colorado, Boulder, Colo., USA; R. Dedonder, Bacillus Genetic Stock Centre, Ohio State University, Columbus, Ohio, USA; C. Anagnostopoulos, Centre de Genetique Moleculaire, CNRS, Gif-Sur-Yvette, France.

$\operatorname{trf} A$ in trans will allow the plasmid to replicate at an elevated copy number. The new plasmid, pCT570, was constructed by combining the ori $V_{\mathrm{RK} 2}$ and $\mathrm{Km}^{\mathrm{R}}$ segment of pCT461 with the replicon and $\mathrm{Tc}^{\mathrm{R}}$ of pLG339 (Fig. 1). A fragment carrying a $\mathrm{Cm}^{\mathrm{R}}$ determinant which can be expressed in $B$. subtilis was then introduced into pCT570 from pHV60 (Fig. 1). The resulting plasmid, pCT571, is $9.5 \mathrm{~kb}$ in size, confers $\mathrm{Km}^{\mathrm{R}}$, $\mathrm{Tc}^{\mathrm{R}}$ and $\mathrm{Cm}^{\mathrm{R}}$ in $E$. coli and $\mathrm{Cm}^{\mathrm{R}}$ in $B$. subtilis and has at least seven unique restriction sites: BamHI, SalI and $S p h \mathrm{I}$ in the $\mathrm{Tc}^{\mathrm{R}}$ gene and HindIII, SmaI and $X h o I$ in the $\mathrm{Km}^{\mathrm{R}}$ gene, allowing insertional inactivation of these markers to be used to screen for insertion of foreign fragments. While pCT571 has ori $V_{\mathbf{R K} 2}$, it lacks $\operatorname{trf} A$, which is essential for $o r i V_{\mathrm{RK} 2}$ activity. Normally, therefore, only the pSC101 replicon functions and the copy number of pCT571 will be six to eight copies per chromosome. However, in a bacterial strain carrying $\operatorname{trf} A$ in trans the copy number of pCT571 will rise.

Plasmid pCT571 cannot replicate in $B$. subtilis; it can only be used to transform $B$. subtilis to $\mathrm{Cm}^{\mathrm{R}}$ if it gains either a $B$. subtilis replicon or chromosomal DNA allowing it to integrate into the chromosome by homologous recombination. We checked that pCT571 can be used to transform $B$. subtilis in this way by inserting into it an approximately $400 \mathrm{bp} \mathrm{BamHI}$ fragment (from pUC99) carrying part of the $B$. subtilis his genes. DNA of this plasmid, pCT572, was used to transform the prototrophic $B$. subtilis strain $\mathrm{PY} 79$ to $\mathrm{Cm}^{\mathrm{R}}$. As expected, $\mathrm{Cm}^{\mathrm{R}}$ transformants were obtained with pCT572 but not pCT571. That integration had occurred by homologous recombination at the his locus was confirmed by checking the His phenotype. If the his fragment in pCT572 contains an internal segment of the his operon then a Campbell-type integration will result in inactivation of the his genes, leading to a $\mathrm{His}^{-}$phenotype. This was indeed observed. Selection for His ${ }^{+}$bacteria subsequently resulted in loss of $\mathrm{Cm}^{\mathrm{R}}$, as expected. Therefore pCT571 behaves as expected in transformation of $B$. subtilis, when it carries a segment of $B$. subtilis DNA (see previous work with integrational vectors, e.g. Piggot et al., 1984). 

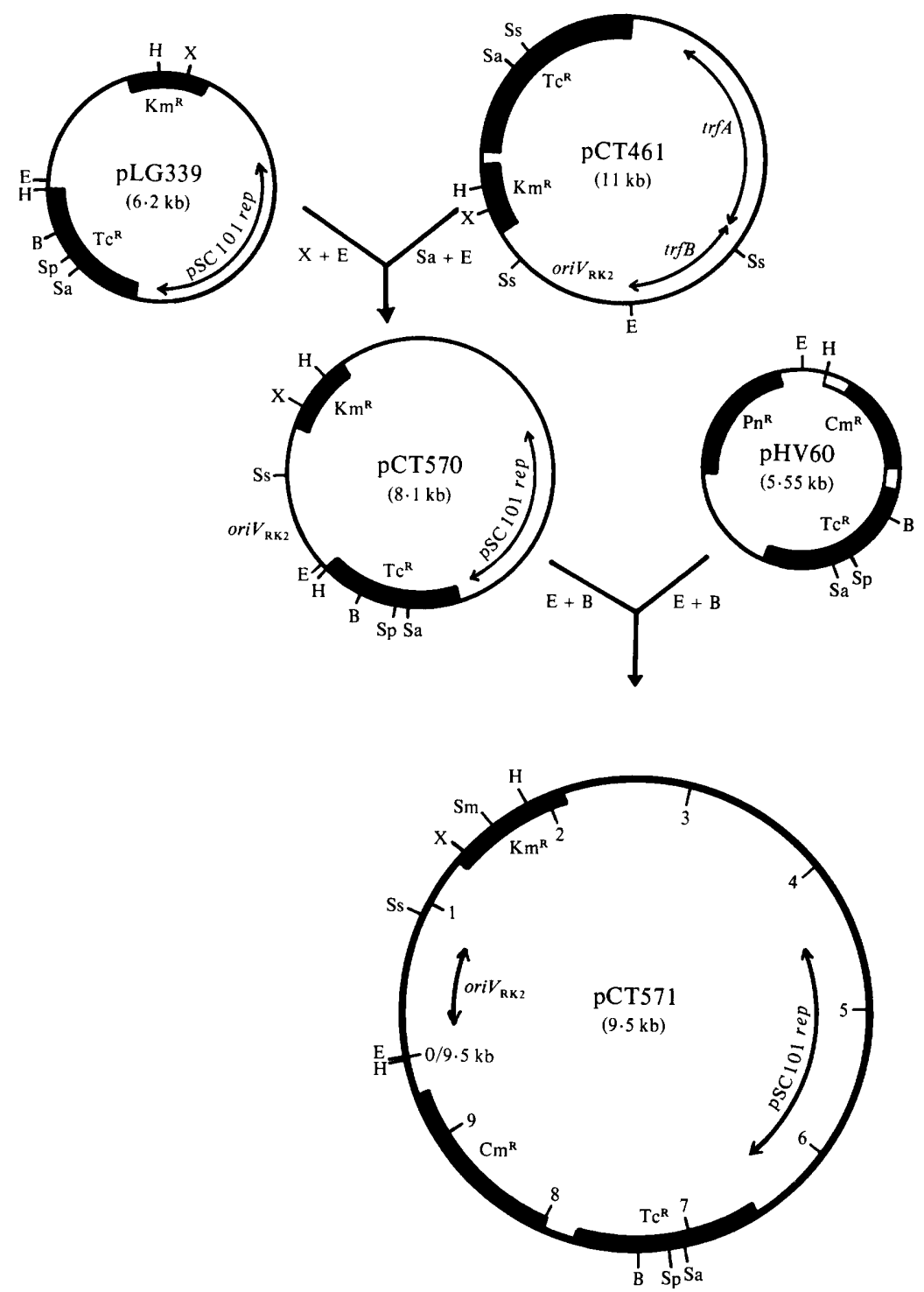

Fig. 1. Construction and structure of pCT571. Genetic loci are as defined in the text. The EcoRI to XhoI segment of pLG339 containing the $\mathrm{Tc}^{\mathrm{R}}$ determinant and $\mathrm{pSC} 101$ replicon were joined to the EcoRI to SalI segment of pCT461 containing $\mathrm{Km}^{\mathrm{R}}$ and ori $V_{\mathrm{RK} 2}$. The resultant plasmid, pCT570, was cut with EcoRI and BamHI and then the EcoRI to BamHI segment of pHV60 carrying $\mathrm{Cm}^{\mathrm{R}}$ was inserted, giving pCT571, which is shown on an enlarged scale. Restriction sites are abbreviated as follows: B, BamHI; E, EcoRI; H, HindIII; Sa, SalI; Sm, SmaI; Sp, SphI; Ss, SstII; X, XhoI.

\section{Gene bank construction and screening}

The $B$. subtilis gene bank was constructed by ligating fragments ranging in size from 4 to $20 \mathrm{~kb}$ of partially Sau3A-digested B. subtilis chromosomal DNA (from PY79), fractionated by sucrose velocity gradient centrifugation, to dephosphorylated BamHI-digested pCT571, and subsequently transforming E. coli strain ED8654, in which pCT571 has a low copy number. DNA of $1097 \mathrm{Km}^{\mathrm{R}} \mathrm{Tc}^{\mathrm{S}}$ colonies was extracted from separate $1.5 \mathrm{ml}$ cultures. Insertion of foreign fragments into pCT571 was confirmed by checking the electrophoretic mobility of the plasmid DNA on $1 \%(\mathrm{w} / \mathrm{v})$ agarose gels with pCT571 as a marker, and was further characterized by 
digesting all plasmids with $E c o R I$. The restriction pattern of some plasmids was also determined after EcoRI and SalI digestion. Out of 1097 plasmids, 120 plasmids were not used for further analysis, because of either having a very small insert or no apparent insert at all. The mean size of the inserted $B$. subtilis DNA segments is approximately $8 \mathrm{~kb}(8 \cdot 15 \pm 3.21)$, as calculated from 75 randomly selected plasmids from the gene bank.

To demonstrate that the cloned DNA fragments represent $B$. subtilis DNA, the ability of a range of plasmids to transform $B$. subtilis to $\mathrm{Cm}^{\mathrm{R}}$ was tested. DNA of 17 plasmid representatives of the gene bank was transformed into low (MV10) and high (MV10Ch3/86) copy number strains and reisolated. For both strains one tenth of the plasmid DNA extracted from $1.5 \mathrm{ml}$ overnight cultures was used to transform B. subtilis strain PY79 to $\mathrm{Cm}^{\mathrm{R}}$. While only four plasmid preparations from the low copy number strain gave any transformants (mean $=1.5$ transformants per transformation of these four), only two of the 17 plasmids failed to give any transformants using DNA from the high copy number strain (mean $=69$ transformants per transformation over all 17). A number of factors may be responsible for this difference. In addition to the greater absolute amount of plasmid DNA from the high copy number strain (greater by a factor of approximately five), the increase may be due to the lower ratio of RNA and chromosomal DNA fragments to plasmid DNA available, or to the increased proportion of plasmid multimers in preparations from the high copy number strain (Canosi et al., 1978). The results show that the hybrid plasmids produced have gained segments with homology to the $B$. subtilis chromosome allowing transformation to $\mathrm{Cm}^{\mathrm{R}}$ by homologous recombination.

After constructing the gene bank, the next step was to determine whether it contained cloned segments representative of the whole $B$. subtilis genome. Genetic loci, generally nutritional markers, representing most regions of the $B$. subtilis chromosome were chosen; the presence of these specific $B$. subtilis genes in the gene bank was tested using pooled plasmid DNA to transform $E$. coli and $B$. subtilis mutant strains, direct selection being applied for the ability to grow in the absence of particular nutritional requirements. In $E$. coli, conversion to prototrophy for particular markers should occur by complementation since it has been shown that $B$. subtilis genes which are expressed during vegetative growth are generally expressed and can function in E. coli (for example, Mahler \& Halvorson, 1977; Nagahari \& Sakaguchi, 1978; Rabinovich et al., 1978; Chi et al., 1978; Moir, 1983). In B. subtilis, conversion to prototrophy should occur by integration of the wild-type sequence into the chromosome.

The bank of 977 hybrid plasmids was first pooled in 95 mini pools consisting of between eight and 11 plasmids per mini pool. For $E$. coli, 95 mini pools were further pooled into nine groups each containing approximately 100 plasmids, whereas for studies in $B$. subtilis, the mini pools were pooled to give 30 batches of approximately 30 plasmids.

The following nutritional markers were chosen to screen the gene bank in E. coli: arg, his, lys, thr, cys A, met-65, pdxC and pyrF30, since in B. subtilis these are distributed over the whole of the $B$. subtilis chromosome. Competent mutant strains were transformed separately with DNA from the nine plasmid pools. Strains with multiple requirements were then spread on supplemented minimal plates, selecting for independence from one different nutritional requirement at a time. Experiments were repeated three times. DNA of plasmids apparently complementing different nutritional markers was extracted from selected transformants, and in each case the corresponding plasmid in the gene bank was determined by comparing their EcoRI and EcoRI plus SalI digestion patterns with those of the individual plasmids comprising the pool. Competent $E$. coli strains with the specific markers were transformed again with both the complementing plasmid and the apparently identical plasmid from the gene bank, to confirm and demonstrate the specificity of the $B$. subtilis genomic segment in that particular plasmid. If possible, plasmids identified in this way in $E$. coli were also used for transformation of appropriate $B$. subtilis strains, to confirm that the results obtained in $E$. coli did indeed genuinely identify specific $B$. subtilis genes. The cumulative results of these experiments are shown in Table 2 and show that a variety of $B$. subtilis genes were identified in this way.

Pooled plasmid DNA was screened in $B$. subtilis by transformation and selection for the prototrophic phenotype of each particular marker. E. coli strain MV10Ch3/86, in which hybrids have a high copy number, was transformed with DNA from each pool to obtain a better yield of 
Table 2. Summary of genetic loci identified in the gene bank

+ , Positive result for complementation $(E$. coli) or transformation (B. subtilis); ++ , more than one plasmid was identified.

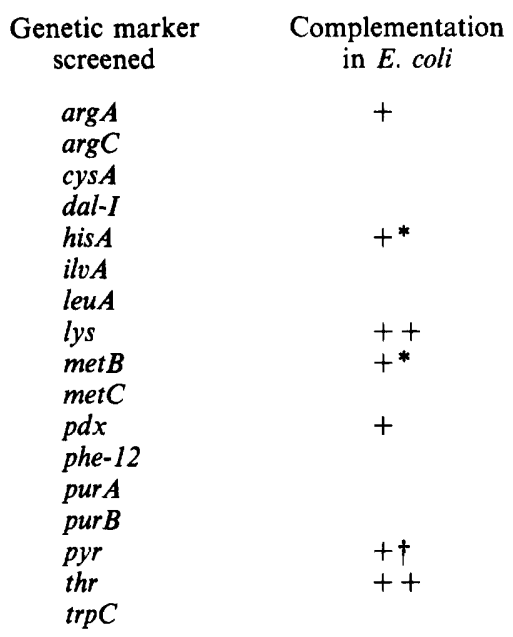
Transformation
of $B$. subtilis

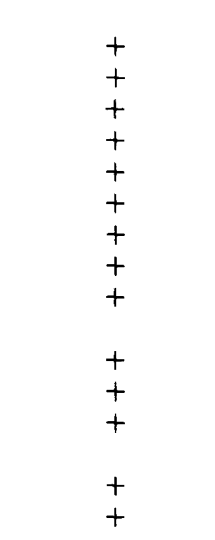

* Genotype of plasmid from E. coli verified in B. subtilis.

$\dagger$ Genotype of plasmid verified by hybridization with pyr probe (Chi et al., 1978).

pooled DNA, since such DNA transformed $B$. subtilis more efficiently than plasmid DNA from the low copy number strain (see above). All transformants from one pool were resuspended together in L broth and used to extract DNA directly and samples of this DNA were used to transform $B$. subtilis strains. In this way the gene bank was screened for the following nutritional markers: $\arg C 4, \operatorname{cys} A 14$, dal-1, his $A 1$, ilvA, leuA, lys-21, metB, metC3, phe-12, purA16, purB6, thr-5, trpC. In each case a significant number of transformants were obtained, indicating the presence of DNA corresponding to these loci in the gene bank. Plasmids identified in transformation experiments for nutritional markers arg, his, lys and met in E. coli were also used to transform phenotypically similar $B$. subtilis mutant strains. The plasmids isolated as complementing the Lys ${ }^{-}$phenotype in $E$. coli failed to give transformants for $l y s-21$ in $B$. subtilis, indicating the probable presence of at least two different lys genes of $B$. subtilis in the gene bank. Plasmids pSHarg 1 and pSH526, which were identified as complementing an Arg- $^{-}$E. coli strain $(\operatorname{argH})$, failed to transform a $B$. subtilis $\operatorname{argC}$ strain to $\mathrm{Arg}^{+}$. It seems likely that pSH526 has a $B$. subtilis genomic segment with $\arg A$ on it (Mountain et al., 1984). Plasmids pSH296 and pSH113, which successfully complemented the his and met mutations respectively in $E$. coli, were subsequently identified as having the genomic segments of $B$. subtilis carrying his $A$ and $m e t B$ genes by transformation experiments in $B$. subtilis. Identical plasmids (pSH993, pSH1012, pSH1018, pSH1022 and pSH1026) which complemented pyr in E. coli hybridized strongly with a $6.7 \mathrm{~kb}$ EcoRI fragment carrying pyrD, $F, E$ and part of $B$, cloned in $\lambda$ by Chi et al. (1978).

While individual plasmids carrying specific markers were identified by complementation in $E$. coli, the screening of pooled plasmids for nutritional markers by transformation of $B$. subtilis was not generally taken as far as the identification of individual plasmids. However, that positive results with pooled DNA can be the starting point for successful isolation of individual hybrid plasmids from this gene bank is illustrated by the isolation of hybrid plasmids carrying the $s d h$ operon and gerE gene (Hasnain et al., 1985). The range of the $B$. subtilis chromosome (Henner \& Hoch, 1980) covered by genes which we have evidence for in the gene bank gives us confidence that a large proportion of all genes can be easily isolated from this gene bank using appropriate screening procedures. 
Table 3. Comparison of the ability of vector and hybrid plasmid DNA to transform low (MV10) and high (MV10Ch3/86) copy number strains

\begin{tabular}{lrr} 
& \multicolumn{2}{c}{ No. of transformants $\dagger$} \\
\cline { 2 - 3 } \multicolumn{1}{c}{ Plasmids } & 162 & MV10Ch3/86 \\
pLG339 & $\sim 5000$ & $\sim 5000$ \\
pCT571 & 406 & $\sim 25000$ \\
pSHpyr2 & 276 & 5 \\
pSH550 & 1318 & 13 \\
pSH550* & 62 & 10 \\
pSH1019 & 0 & 2250 \\
pSH1019* $\ddagger$ & 0 & $\sim 5000$ \\
No plasmid DNA & 0
\end{tabular}

† For pLG339 and pCT571, approximately $1 \mu \mathrm{g} \mathrm{CsCl} /$ ethidium bromide purified DNA was used. For the other plasmids, one tenth of the DNA yielded from a $1.5 \mathrm{ml}$ overnight culture by the alkaline SDS method was used.

$\ddagger$ Plasmid DNA designated pSH550* and $\mathrm{pSH} 1019^{*}$ was extracted from MV10Ch3/86 which had been transformed with pSH550 and pSH1019 respectively (see Results).

\section{Stability of hybrid plasmids}

As already described in the Introduction, difficulties encountered in cloning and stably maintaining hybrid plasmids at high copy number were the primary reasons for constructing the gene bank in the low copy number plasmid pCT571. In order to determine whether or not this strategy allows one to clone segments which cannot be cloned at high copy number, we exploited the fact that in a strain carrying the $\operatorname{trf} A$ gene of RK2 the mutant ori $V_{\mathrm{RK} 2}$ in pCT571 is functional and the copy number of pCT571 increases to 35-40 copies per chromosome equivalent. Under these circumstances we found that plasmids from the gene bank behaved in one of a number of different ways. Described in some detail below are examples of the major categories of plasmid found.

The first category of plasmid are those which cannot be introduced into the high copy number strain MV10Ch3/86. Examples of such plasmids are pSH550 and pSHpyr2, which are probably identical and which contain an approximately $7.5 \mathrm{~kb}$ insert, apparently carrying at least part of the $B$. subtilis Pyr genes. While with both pLG339 and pCT571the number of transformants was greater in MV10Ch3/86 than in MV10 (which probably reflects competence of the bacteria, since replication of $\mathrm{pSC} 101$ is not affected by $\operatorname{trfA}$ ), it was observed that the number of transformants obtained using DNA of pSH550 and pSHpyr2 was substantially higher in MV10 than in MV10Ch3/86 (Table 3). Plasmid DNA extracted from transformants of the high copy number strain contained various kinds of deletions or insertions as compared with pSH550. Even between the colonies from a single transformation experiment different $E c o R I$ restriction patterns were observed, while no change in plasmid DNA from the low copy number strain was observed. It seemed possible that the deletions or insertions observed may have inactivated a function on the $B$. subtilis genomic segment in pSH550 which was deleterious at high copy number. Therefore plasmid DNA designated pSH550*, extracted from MV10Ch3/86 (in which hybrids based on pCT571 have a high copy number) which had been transformed with pSH550, was tested for its ability to retransform MV10 and MV10Ch3/86 efficiently. While there was an apparent increase in transformation efficiency for MV10, the number of transformants in MV10Ch3/86 was again very low (Table 3), and plasmid DNA extracted from the transformants of MV10Ch3/86 showed further changes in plasmid restriction pattern compared to $\mathrm{pSH} 550^{*}$, while no change was observed in MV10. Although we do not yet know the reason for our inability to establish pSH550 in MV10Ch3/86, it does appear that the defect is not entirely removed by the changes in plasmid structure which apparently allow the plasmid to become established in MV10Ch3/86. Nor have we established at what stage the plasmid variant derivatives arise. It is possible that they represent spontaneous events in the strain from which the plasmid DNA was isolated. Alternatively they may represent derivatives which arise after 
Table 4. Transformation activity and stability of various hybrid plasmids in low (MV10) and high (MV10Ch3/86) copy number strains

\begin{tabular}{|c|c|c|c|c|c|}
\hline \multirow[b]{2}{*}{ Plasmid } & \multirow{2}{*}{$\begin{array}{c}\text { Size of } \\
B . \text { subtilis } \\
\text { segment }(\mathrm{kb})\end{array}$} & \multicolumn{2}{|c|}{ No. of transformants* } & \multicolumn{2}{|c|}{ Changes observed $\uparrow$} \\
\hline & & MV10 & $\mathrm{MV} 10 \mathrm{Ch} 3 / 86$ & Low copy strain & High copy strain \\
\hline $\mathrm{pSH} 2$ & 7 & 18 & 75 & - & After 6 weeks \\
\hline pSH4 & 9 & 266 & 720 & - & - \\
\hline pSH8 & 5 & 150 & 1120 & - & - \\
\hline pSH29 & 13 & 56 & 120 & - & - \\
\hline pSH225 & 12 & 93 & 850 & - & - \\
\hline pSH245 & 12.5 & 71 & 510 & - & - \\
\hline pSH359 & 9 & 288 & 1200 & - & - \\
\hline pSH408 & 10 & 54 & 432 & - & - \\
\hline pSH471 & 11 & 133 & 520 & - & - \\
\hline pSH546 & $3 \cdot 5$ & 560 & 1500 & - & - \\
\hline pSH658 & 9 & 94 & 1230 & - & - \\
\hline pSH679 & 12 & 245 & 530 & After 19 weeks & After 13 weeks \\
\hline pSH692 & 10 & 259 & 1100 & - & After 26 weeks \\
\hline pSH715 & 16 & 67 & 620 & After 6 weeks & After 6 weeks \\
\hline pSH749 & 4.5 & 448 & 915 & - & After 26 weeks \\
\hline pSH763 & 8 & 243 & 1320 & - & - \\
\hline pSH 1024 & $12 \cdot 5$ & 230 & 510 & - & - \\
\hline pSH1041 & 8 & 500 & 1500 & - & After 13 weeks \\
\hline
\end{tabular}

* Plasmid DNA was extracted by the alkaline/SDS method and one tenth of the yield from a $1.5 \mathrm{ml}$ overnight culture was used for each transformation.

$\dagger$ In some cases $(-)$ no change was observed after 32 weeks; where changes were observed, the time of their earliest appearance is recorded.

transformation into the high copy number recipient. However, it is clear that the parent plasmid itself, pSH550, is unable to become established in the high copy number strain.

The second category of plasmid are those plasmids which can be introduced efficiently into the high copy number host but which are apparently maintained poorly and rapidly give rise to deletion derivatives. An example of such a plasmid is pSH1019, which has an approximately $20 \mathrm{~kb}$ insert that from hybridization data appears also to carry at least part of the $B$. subtilis pyr genes. This plasmid gave many more transformants in $\mathrm{MV} 10 \mathrm{Ch} 3 / 86$ than in $\mathrm{MV} 10$, but plasmid DNA extracted from cultures grown from three randomly selected transformants of MV10Ch3/86 showed only small amounts of plasmid DNA in contrast to the increase in copy number expected. The EcoRI restriction pattern obtained suggested that the plasmids present were identical to $\mathrm{pSH} 1019$ isolated from the low copy number strain. However, if transformants were not used to extract DNA immediately but were stored at room temperature, then within $24 \mathrm{~h}$, deletion derivatives could be identified in the plasmid DNA extracted. When plasmid DNA extracted from such transformants, designated pSH1019*, was used to transform MV10 and MV10Ch3/86, the transformation frequency in MV10Ch3/86 was high (Table 3) but no transformants were obtained in MV10. A possible explanation for this is that the deletion derivatives obtained have not only lost part of the inserted $B$. subtilis DNA segment but also part of the pSC101 replicon that is essential for plasmid replication in MV10. Thus, while the hybrid plasmid pSH1019 can be introduced into the high copy number strain, it rapidly gives rise to deletion derivatives which are maintained in preference to the parent.

The examples of plasmids in these first two categories were encountered by chance when investigating plasmids carrying the pyr genes of $B$. subtilis. A third category of plasmid, those which in the short to medium term are stable at both low and high copy number were encountered when 18 plasmids from the gene bank were selected for study of hybrid plasmid stability. These plasmids were selected by virtue of their possession of reasonably large segments of $\boldsymbol{B}$. subtilis DNA (between 5 and $15 \mathrm{~kb}$ ) so as to optimize the likelihood of encountering $\boldsymbol{B}$. subtilis loci which may be deleterious at high copy number. For each of these plasmids, the number of transformants obtained in MV10Ch3/86 was greater than in MV10 (Table 4), 
although the absolute number of transformants varied considerably. Plasmid DNA isolated from both high and low copy number strains looked identical with respect to restriction pattern, except for the expected increase in quantity of DNA in the MV10Ch3/86 strains. To study the long-term stability of hybrid plasmids, a single transformant was streaked to single colonies on selective medium and after growth at $37^{\circ} \mathrm{C}$ was stored at room temperature. Plasmid DNA in these cultures was examined after $6,13,19,26$ and 32 weeks by inoculating $1.5 \mathrm{ml} \mathrm{L}$ broth supplemented with kanamycin.

Observations from these studies on long term stability fall into three groups (Table 4). First, plasmids which showed no detectable change in their EcoRI restriction pattern after storage in either low or high copy number strain over 32 weeks. Second, plasmids (pSH2, pSH692, pSH749 and pSH1041) which exhibited insertions and deletions only in the high copy number strain. Third, plasmids (pSH715 and pSH679) which suffered deletions in both low and high copy number strains, although with pSH679, deletions were observed earlier in the high copy number strain. Generally, changes, if they occur, lead to loss of the parental plasmid restriction pattern and the production of what seems to be a mixture of derivatives. In most cases the composition of the mixture changed with time, eventually resulting in one predominant derivative. In the case of pSH1041 and pSH679, these final stable forms were small plasmids which had lost all EcoRI restriction sites, indicating that the deletions had extended well into the vector DNA. DNA extracts of all 18 plasmids from the low copy number strain kept at $4{ }^{\circ} \mathrm{C}$ showed no changes in EcoRI restriction pattern even after 6 months. It appeared that temperature also contributed to the instability observed in the DNA of the hybrid plasmids.

\section{DISCUSSION}

The aim of this work was to construct in $E$. coli as complete a gene bank of $B$. subtilis as possible, using a low copy number vector whose copy number can be increased when desired, and so to determine whether construction of a gene bank at low copy number allows one to clone DNA segments which it would be difficult or impossible to clone in a high copy number plasmid. The vector which we have constructed for this purpose, pCT571, appears to work well. It differs from dual replicon runaway vectors (Andreoli, 1985) in being maintained stably at high copy number with no apparent harm to the host cell. On the other hand it does seem to be maintained at sufficiently high copy number, when the RK2 replicon is activated, to unmask at least some of the consequences of trying to maintain some $B$. subtilis chromosomal segments at high copy number.

In the low copy number strain pCT571 seems to be very suitable for constructing a gene bank. The pSC101 replicon, while having a relatively low copy number, yields enough plasmid DNA by rapid isolation methods to allow easy analysis of clones. Screening of the hybrids produced indicates that many of the clones contain large $B$. subtilis chromosome segments. By a combination of complementation in $E$. coli and recombination in $B$. subtilis we have shown the presence of markers which come from all regions of the chromosome. The fact that all auxotrophic mutants of $B$. subtilis tested could apparently be transformed to prototrophy by one or other of the pools of hybrid plasmids encourages us to think that the gene bank covers most of the genome. Using the formula of Clarke \& Carbon (1976) we calculate that that probability of any given sequence of the $B$. subtilis genome being present in our gene bank is about $90 \%$. Where we have studied a hybrid plasmid from the gene bank in detail (carrying the $s d h$ operon and gerE; Hasnain et al., 1985), the evidence suggests that the hybrids obtained contain a single segment of the genome with the same structure as in the $B$. subtilis chromosome, and that this genomic segment is maintained reasonably stably in contrast to the instability observed in a similar segment recently reported as having been cloned on a high copy number plasmid (Magnusson et al., 1985). In addition, experiments with a hybridization probe show that for a given region of the genome (in this case the pyr operon) there are a number of clones containing non-identical but overlapping segments of the genome (Hasnain, 1985). Thus, not only does this gene bank cover most of the chromosome but it should also provide an opportunity to 'walk' from known and easily selected genes into less well defined regions. It is also stored as DNA of 
individual hybrids and should not therefore be subject to loss of physically unstable or poorly replicating hybrids, as found in previously constructed gene banks (Rapoport et al., 1979; Ferrari et al., 1981; Ostroff \& Pène, 1984a, b).

The gene bank provided us with the opportunity to study the effects of vector plasmid copy number on the cloning and long term maintenance of $B$. subtilis chromosomal DNA. While a random sample of hybrids carrying large inserts showed no instability in the short term, during the course of this work we did come across a number of hybrids which could not exist stably at high copy number. Both of the plasmids of this sort reported in this paper carry B. subtilis DNA from the region coding for the pyr operon (Hasnain, 1985). We do, however, have another hybrid, pSH1012, which complements $E$. coli pyr mutants and hybridizes strongly with the $\lambda$ pyr isolated by Chi et al. (1978) that carries at least part of the $B$. subtilis pyr operon, and this plasmid is stable at high copy number. It is possible that the unstable plasmids carry deleterious genes absent from pSH1012. Alternatively, the unstable plasmids may lack regulatory elements which normally stop the over-production of deleterious gene products. A phenomenon which may be explained in the latter way has been described by Mountain et al. (1984), who cloned EcoRI fragments of the $B$. subtilis genome in $E$. coli using pBR322 as a vector. They found that a $12 \mathrm{~kb}$ fragment of hybrid plasmid pUL720, which complemented $E$. coli mutant strains defective for $\arg A, B, C, D, E, F / I, \operatorname{cer} A$ and $\operatorname{cer} B$, can only be maintained intact in the presence of a second EcoRI fragment, from elsewhere on the $B$. subtilis chromosome, that appears to code for the arg repressor gene (Mountain et al., 1985). They suggest that one of the products of the arg operon is host lethal in $E$. coli if transcription is not regulated.

Deletion derivatives arise from unstable plasmids at various stages. For pSH550, which cannot be transformed intact into the high copy number strain, it seems likely that the few transformants obtained may arise from deletion derivatives present in trace quantities in the plasmid DNA of the low copy number strain. With plasmids which can be introduced efficiently into the high copy number strain it is likely that derivatives arise within this strain itself. However, it is unclear whether the unstable plasmids promote structural instability or simply have a sufficiently deleterious effect on their host that bacteria with deletion derivatives have a major advantage. This question is particularly intriguing with respect to bacteria carrying hybrid plasmids that are stored at room temperature, since we do not know whether the appearance of plasmid derivatives after many weeks of storage results from preferential survival of bacteria carrying them. Whatever the underlying mechanism giving rise to the deletion derivatives, it is clear from the studies on long term stability that storage of high copy number hybrid plasmids at room temperature can lead to loss of the plasmid. Use of low copy number vectors helps to overcome this problem and storage at $4{ }^{\circ} \mathrm{C}$ provides effectively stable maintenance. Nevertheless, storage of isolated plasmid DNA is probably even more reliable.

Thus, the use of low copy number vectors in gene bank construction has been shown to provide a way of avoiding the considerable problems of genetic instability created by the use of high copy number vectors. We hope that the gene bank constructed in this study will prove useful in the isolation and analysis of previously uncharacterized regions of the $B$. subtilis chromosome.

We thank all those who provided bacterial strains and plasmids used in this work; D. R. Helinski, J. R. Guest, N. Sueoka, R. Dedonder, C. Anagnostopoulos, N. Stoker and Myra Jacobs. In addition we thank H. Howell, C. Price and J. Yeomans for technical assistance, E. Badger for help in preparation of the manuscript and especially R. Sammons and I. Roberts for useful advice and discussion during the course of this work. S. H. was the recipient of a Pakistan Government Scholarship and part of this work was financed by a Faculty Research Grant awarded to C.M.T.

\section{REFERENCES}

Anagnostopoulos, C. \& Spizizen, J. (1961). Requirements for transformation in Bacillus subtilis. Journal of Bacteriology 81, 741-746.

ANDREOLI, P. M. (1985). Versatile Escherichia coli-
Bacillus shuttle vectors derived from runaway plasmids related to CloDF13. Molecular and General Genetics 199, 372-380.

Banner, C. D. B., Moran, C. P., JR \& Losick, R. 
(1983). Deletion analysis of a complex promoter for a developmentally regulated gene from Bacillus subtilis. Journal of Molecular Biology 168, 351-365.

BIRNBoIM, H. C. \& Doly, J. (1979). A rapid alkaline extraction procedure for screening recombinant plasmid DNA. Nucleic Acids Research 7, 1513-1523.

Canosi, U., Morelli, G. \& Trautner, T. A. (1978). The relationship between molecular structure and transformation efficiency of some $S$. aureus plasmids isolated from B. subtilis. Molecular and General Genetics 166, 259-267.

ChI, N.-Y. W., Ehrlich, S. D. \& Lederberg, J. (1978). Functional expression of two Bacillus subtilis genes in E. coli. Journal of Bacteriology 133, 816-821.

Clarke, L. \& Carbon, J. (1976). A colony bank containing synthetic ColEl hybrid plasmids representative of the entire $E$. coli genome. Cell 9, 91-99.

Ferrari, E., Henner, D. J. \& Hoch, J. A. (1981). Isolation of Bacillus subtilis genes from Charon 4A Library. Journal of Bacteriology 146, 430-432.

GryCZAN, T. J. \& DuBNaU, D. (1982). Direct selection of recombinant plasmids in Bacillus subtilis. Gene 20, 459-469.

HASNAIN, S. (1985). Construction and analysis of a novel gene bank of B. subtilis: cloning of the sdh and gerE loci. PhD thesis, University of Birmingham, UK.

Hasnain, S., SAmmons, R., Roberts, I. \& Thomas, C. M. (1985). Cloning and deletion analysis of a genomic segment of Bacillus subtilis coding for $s d h A$, $B, C$ (succinate dehydrogenase) and ger $E$ (spore germination) loci. Journal of General Microbiology 131, 2269-2279.

HeNNER, D. J. \& Hoch, J. A. (1980). The Bacillus subtilis chromosome. Microbiological Reviews 44, 5782.

Hutchinson, K. W. \& Halvorson, H. O. (1980). Cloning of randomly cleaved DNA fragments from a $\phi 105$ lysogen of Bacillus subtilis: identification of prophage containing clones. Gene 8, 267-278.

KahN, M., Kolter, R., Thomas, C., Figurski, D., Meyer, R., Remaut, E. \& Helinski, D. R. (1979). Plasmid cloning vehicles derived from plasmids ColE1, F, R6K and RK2. Methods in Enzymology 68, 268-280.

Magnusson, K., Hederstedt, L. \& Rutberg, L. (1985). Cloning and expression in Escherichia coli of $s d h A$, the structural gene of cytochrome $b_{558}$ of the Bacillus subtilis succinate dehydrogenase complex. Journal of Bacteriology 162, 1180-1185.

MAHLER, I. \& HALVORSON, H. (1977). Transformation of Escherichia coli and Bacillus subtilis with a hybrid plasmid molecule. Journal of Bacteriology 131, 374377.

Maniatis, T., Hardison, R. C., Lacy, E., Laver, J., O'Connell, C., Quon, D., Sim, D. K. \& EfstratiaDIS, A. (1978). The isolation of structural genes from libraries of eukaryotic DNA. Cell 15, 687-701.

MARMUR, J. (196l). A procedure for the isolation of DNA from microorganisms. Journal of Molecular Biology 3, 208-218.

MoIR, A. (1983). The isolation of $\lambda$ transducing phages carrying the cit $G$ and ger $A$ genes of Bacillus subtilis. Journal of General Microbiology 129, 303-310.

Mountain, A., Mann, N. H., Munton, R. N. \& BAUMBERG, S. (1984). Cloning of a Bacillus subtilis restriction fragment complementing auxotrophic mutants of eight Escherichia coli genes of arginine biosynthesis. Molecular and General Genetics 197, 8289.

Mountain, A., Smith, M. C. M. \& Baumberg, S. (1985). A Bacillus subtilis DNA fragment prone to deletion on cloning in Escherichia coli and its stabilization. The Society for General Microbiology Quarterly 12, part 3, M19.

MURRay, N. I., Brammar, W. J. \& MURRay, K. (1977). Lambdoid phage that simplify the recovery of in vitro recombinants. Molecular and General Genetics 150, 53-61.

Nagahari, K. \& SaKaguchi, K. (1978). Cloning of Bacillus subtilis leucine $A, B$ and $C$ genes with Escherichia coli plasmids and expression of the leuC gene in E. coli. Molecular and General Genetics 158, 268-270.

OsTrofF, G. R. \& PÈNE, J. J. (1984a). Molecular cloning with bifunctional plasmid vectors in Bacillus subtilis. I. Construction and analysis of a B. subtilis clone bank in Escherichia coli. Molecular and General Genetics 193, 299-305.

OstrofF, G. R. \& PÈnE, J. J. (1984b). Molecular cloning with bifunctional plasmid vectors in Bacillus subtilis. II. Transfer of sequences propagated in Escherichia coli to B. subtilis. Molecular and General Genetics 193, 306-311.

Piggot, P. J., Curtis, C. A. M. \& de Lencastre, H. (1984). Use of integrational plasmid vectors to demonstrate the polycistronic nature of a transcriptional unit (spoIIA) required for sporulation of Bacillus subtilis. Journal of General Microbiology 130 , 2123-2136.

Primrose, S. B. \& Ehrlich, S. D. (1981). Isolation of plasmid deletion mutants and a study of their instability. Plasmid 6, 193-201.

RABINOVICH, N. M., YUbebYROV, M., LINEVICH, Z. K., BANDRIN, S. V. \& STEPANOV, A. I. (1978). Expression of the riboflavin operon of Bacillus subtilis in cells of Escherichia coli in the composition of hybrid plasmids pPR1 and pPR2. Doklady Akademii nauk SSSR 238, 1459-1461 (summary in Genetics $A b$ stracts, vol. 11, no. 3).

Rapoport, G., Klier, A., Billaut, A., Fargette, F. \& DEDONDER, R. (1979). Construction of a colony bank of $E$. coli containing hybrid plasmids representative of the Bacillus subtilis 168 genome. Molecular and General Genetics 176, 239-245.

Smith, C. A. \& Thomas, C. M. (1983). Deletion mapping of kil and kor functions in the $\operatorname{trf} A$ and $\operatorname{tr} f B$ regions of broad host range plasmid RK2. Molecular and General Genetics 190, 245-254.

Stoker, N. G., Fairweather, N. F. \& Spratt, B. G. (1982). Versatile low-copy-number plasmid vectors for cloning in Escherichia coli. Gene 18, 335-341.

Thomas, C. M. (1981). Complementation analysis of replication and maintenance functions of the broad host range plasmids RK2 and RP1. Plasmid 5, 277291.

Thomas, C. M. (1983). Instability of a high copy number mini-plasmid derived from broad host range IncP plasmid RK2. Plasmid 10, 184-195.

Thomas, C. M., Stalker, D. M. \& Helinski, D. R. (1981). Replication and incompatibility properties of segments of the origin region of replication of the 
broad host range plasmid RK2. Molecular and General Genetics 181, 1-7.

Thomas, C. M., Cross, M. A., Hussain, A. A. K. \& SMITH, C. A. (1984). Analysis of copy number control elements in the region of the vegetative replication origin of the broad host range plasmid RK2. EMBO Journal 3, 57-63.

Vieira, J. \& Messing, J. (1982). The pUC plasmids, an M13mp7-derived system for insertion mutagenesis and sequencing with synthetic universal primers. Gene 19, 259-268.

Youngman, P. J., Perkins, J. B. \& Losick, R. (1984). Construction of a cloning site near one end of Tn917 into which foreign DNA may be inserted without affecting transposition in Bacillus subtilis or expression of the transposon borne erm gene. Plasmid 12, 1 9. 